Word count: 8,749

Urban water conservation through customised water and end-use information Ariane Liu a*, Damien Giurco a, Pierre Mukheibir a

a Institute for Sustainable Futures, University of Technology Sydney, NSW, Australia

* Corresponding author. Institute for Sustainable Futures, University of Technology Sydney, P.O. Box 123 Broadway, New South Wales 2007, Australia. Tel.: +61 29514 4972. Fax.: +61 295144941.

Emails: ariane.liu@uts.edu.au (A. Liu), damien.giurco@uts.edu.au (D. Giurco), pierre.mukheibir@uts.edu.au (P. Mukheibir).

URL: http://www.isf.uts.edu.au 


\section{Urban water conservation through customised water and end-use information}

\section{Abstract}

Water conservation in urban centres is an ongoing challenge in which new technologies can play an important role. Smart water metering in conjunction with end-use analysis enables the collection of more detailed information on household water consumption than was previously possible. This presents a new and currently underexplored opportunity to promote more efficient water use via the provision of detailed customised water-use information to householders. Among the variety of possible approaches, is the option of paper-based reports containing a highly detailed 'snapshot' of household water use. This paper describes a mixed methods study in which customised paper-based 'Home Water Updates' were provided to a group of households in Australia to explore the idea of providing detailed feedback, including detailed end-use consumption information on uses of water within the home. The methods used within this research are described in detail to disseminate experience in this relatively new area of research. Analysis of the postintervention householder evaluation survey showed the provision of detailed water-use information via the Home Water Updates appealed to the vast majority of householders; and further resulted in changed behaviours (e.g. shorter showers and full washing machine loads) and installations of new infrastructure. These research findings suggest a potential role for customised household water and end-use information via smart metering. However, more work is required to optimise approaches to enable a significant contribution towards more sustainable urban water management.

\section{Keywords}

Smart water metering; End-use analysis; Residential water conservation; Information; Feedback; Sustainable water.

\section{Introduction}

As the need for greater sustainability in urban centres becomes increasingly apparent (Agudelo-Vera et al., 2012, 2011; McCormick et al., 2013), new technologies and behaviours which can contribute to a more sustainable consumption of important resources are becoming of increasing interest. In particular, ways to reduce consumption of energy and water require the attention of researchers, industry professionals and consumers alike.

Smart metering is an innovative measurement technology which offers the potential to contribute to a more efficient use of electricity, gas and water resources in both commercial and residential buildings. Essentially, smart metering technologies introduce new opportunities to collect more detailed information on resource consumption practices and patterns than was previously possible under conventional metering. The opportunity exists to convey this information both to the utility and the consumer to inform and guide water management (Boyle et al., 2013). Particularly in the water sector, however, comparatively less attention has been on the communication of the detailed water-use information to customers.

\subsection{Water consumption data advances}

Within the water sector, residential meters have traditionally been read once per quarter, yielding just four data points per meter per year (Britton et al., 2008). By contrast, smart water meters record the flow of water 
consumption every set number of seconds (e.g. every 15 or 60 seconds). The technology therefore opens the door to significantly greater data resources and the possibility of understanding water consumption according to time of use within the day, taking also variations in weather and seasonal changes into consideration. Further analysis of detailed smart water meter data can be conducted using trace flow (end-use) analysis, a process which assigns end-use tags (e.g. shower, toilet, washing machine etc.) to each water-using event (Willis et al., 2009). This allows metrics to be obtained for each individual water-using event including start and finish time, duration, flow rate (maximum, minimum, average) and volume (Liu et al., 2013; Mayer et al., 2000). This analysis of high resolution water consumption data collected via smart water metering can therefore prelude a detailed understanding of where water is used in the home (Giurco et al., 2010). This can in turn be used to support more targeted water conservation efforts as well as to assess the effectiveness of demand management interventions (Stewart et al., 2010).

\subsection{Water conservation and the role of information campaigns and detailed feedback}

Water utilities and public agencies around the world have at times used information campaigns to encourage residential water conservation. A variety of modes have been used to inform households of ways to save, including leaflets, bill inserts and websites. The particular mode of informational delivery (e.g. paper versus online) is likely to have implications for its reach. Similarly, the content of water-use information and its format may influence impacts on consumption behaviours. Here an important distinction needs to be drawn between generic information (e.g. aggregate data for a supply location) and disaggregated feedback at the household level. To date, water conservation campaigns have been based on the former, often presented in terms of averages. However, as explained by Aitken et al. (1994), customised feedback can provide a more accurate basis for assessment and action thereby enabling progress towards a (conservation) goal. Therefore, disaggregated water-use feedback may promote conservation at the individual and household levels. Moreover, the more detailed or specific that the customised feedback is, the clearer the signal of real water-saving opportunities may be.

Information-based approaches are often linked to an 'information deficit' model of rational behaviour (Burgess et al., 1998), which suggests households will respond to additional information to their own gains. However, the explanation is not without its critics, which have questioned whether the provision of information alone is effective, or if additional interventional support may be required (e.g. McKenzie-Mohr and Smith, 1999); or whether a focus on information is wrong, since households may depart from the assumptions of rationality in various important ways (e.g. Shove, 2010). Yet these critiques are not specifically levelled at particular types or levels of information, which could plausibly yield varying impacts.

\subsection{Householder smart metering opportunity}

The high resolution data obtained from smart meters creates the potential for far greater informational resources than under traditional metering. The data collected can be analysed with the goal of providing significantly more detailed household-specific information to household water consumers for a potentially more effective provision of information to promote conservation (Liu et al., 2013). 
Until now, however, more research has been conducted within the residential energy sector on the potential role of customised feedback via smart metering (see e.g. Darby, 2010; Faruqui et al., 2010 for reviews). While a couple of residential energy-focused studies took novel steps to incorporate real-time online water use feedback, the impacts on water consumption were comparatively small (3\% in Petersen et al., 2007), or not reported (Fróes Lima and Portillo Navas, 2012). Over the past few years, a handful of studies have emerged specifically investigating the impact of more detailed, customised water-use information via smart water metering. Studies involving paper-based interventions e.g. leak notification letters (Britton et al., 2013) and feedback postcards (Fielding et al., 2013), as well as in-home displays (Doolan, 2010; Wetherall, 2008) and online portals (Erickson et al., 2012; Joo et al., 2014), have reported a positive impact of between 5-10\% water savings. The opportunity still remains, however, to allow householders to engage with a variety of detailed types of water-use feedback, including at end-use levels.

\subsection{Research aims}

This research belongs to a larger program which investigates the potential for detailed water-use information obtained via household smart metering to promote behavioural changes towards more sustainable water consumption. Within this wider scope, this paper explores how householders respond to the provision of detailed, household-specific water and end-use information communicated specifically via paper-based reports ${ }^{1}$. A unique variety of detailed and water-use measures are presented within the study to specifically allow householders to experience different types of information. The study adopts a mixed methods approach in which the impacts of detailed water-use information are analysed using smart meter and end-use data, with the novel inclusion of a post-intervention householder evaluation survey. The study methods and limitations are further described in detail. Deeper insights are thus provided into the approaches adopted to guide future industry and research activities within the emerging field of household smart water metering, end-use analysis and feedback programs.

\section{Materials and methods}

\subsection{Background}

The study location is Tea Gardens/Hawks Nest, suburbs located within the service area of MidCoast Water (MCW) in New South Wales, Australia. In a prior study (2009-2011) MCW introduced smart metering to 141 homes in the area to investigate the impact of pressure management on household water demand. To compare pre- and post-intervention water use the 'Datamatic Firefly' loggers were set each summer (December/January) and winter (June to August) to record water use intensively for a period of between two to five weeks each. This water-use data, which is collected at one-minute intervals with a resolution of 0.5 litres per pulse, is subsequently analysed by MCW using Smartmon software (Redskink Pty Ltd., 2011) to disaggregate the flow data into end-uses (i.e. shower, toilet, washing machine, taps, outdoors and leaks).

\footnotetext{
1 The comparative role for online water-use information will be investigated within the greater ongoing research project in 2015.
} 
While the smart metering technology has since remained in place, and moreover the detailed data is continually being collected each summer and winter and also being disaggregated to end-use levels, no detailed data had previously been communicated to the residents of the smart metered homes. This existing organisational setting therefore led to an interesting opportunity to explore the idea of communicating smart water meter information to the respective households, which forms the focus of the present 'Home Water Update' study (2012-14). Importantly, the existing setting provided a relatively low-cost research environment, since the metering and end-use analysis technologies and the data collection and analysis processes were all already in place. However, corresponding process limitations must simultaneously be acknowledged and their wider implications for future research and industry practice discussed.

\section{2 study design}

A detailed summary of the key HWU study processes is shown in Fig. 1 to provide a comprehensive overview of the requirements of the research study. However, future research programs or implementations might vary in multiple aspects from those listed (e.g. according to budgetary conditions and specific goals). Key HWU study processes are described in more detail in the sub-sections that follow. 


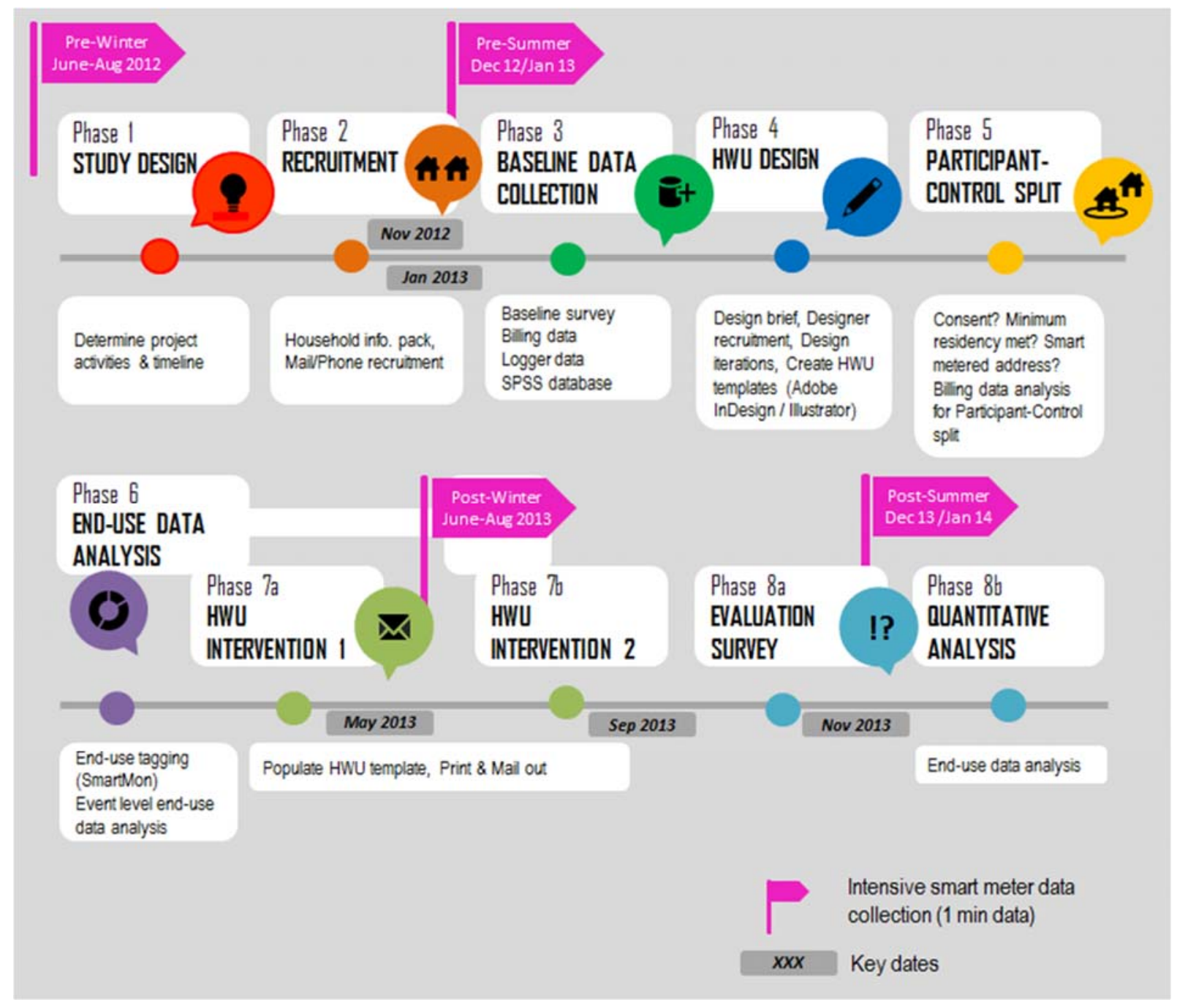

Fig. 1. HWU study design

\subsection{Study participants}

Study participants were recruited via informed consent from the existing pool of 141 smart metered homes. An information pack about the research, which included a baseline survey, was mailed in November 2012 to invite participation in the study. Households willing to participate in the research were required to complete and return the baseline survey and provide written consent to the analysis of their smart meter water consumption and survey data and to potentially being selected to receive more detailed information on their water use. A second round of information packs was mailed to nonrespondents in January 2013, followed by recruitment phone calls in order to increase the sample size and representativeness of a wider population. An incentive of an AUD \$50 rebate on their water bill was offered to all participants to compensate for the time required to complete the survey.

The recruitment processes yielded a total of 79 respondents. Several exclusions were made from the study due to an insufficient length of 
residence at the smart metered address; the respondent no longer residing at the targeted address; duplicate responses from the same household; missing consent statements; and a vacant property. The overall initial sample size for the study came to 68 households.

In terms of household demographics, data collected via the baseline survey showed the study sample was characterised by:

- A median pre-tax household income within the AUD \$30,000 - 59,999 bracket.

- Two occupants per household for the majority (69\%); 13\% had just one occupant; 10\% had three occupants; 6\% had four occupants; just one household had 6 occupants.

- 44\% female and 47\% male respondent gender, with the remainder not reported.

- Median and mode age within the more elderly category i.e. older than 65 years.

- Employment status of respondents was 64\% retired, 33\% in employment and 3\% unemployed.

In terms of household water-appliance stock:

- 79\% of households' toilets were all dual-flush; 13\% had only single-flush toilets; and the remainder had a mix of these.

- 58\% of households were completely fitted out with efficient shower heads; 28\% did not have any efficient shower heads; the remainder again had a mix. - 88\% of households had a top loader washing machine; while 10\% had a front loader.

\subsection{Treatment groups}

The study involved an intervention group and a control group. A stratified randomisation approach was used to distribute the 68 households to either of the equally sized groups $(\mathrm{N}=34)$. The households were first divided into approximate decile groups on the basis of the previous year's water consumption using billing data, before random assignment within each decile to either group. Repeated randomisations were conducted to select approximately similar water consumption distributions between the resulting intervention and control groups. Similarly, the corresponding distributions for the number of occupants per household were compared to check for a balanced distribution between the two groups.

The paper-based intervention medium for the study was the so-called 'Home Water Update' (HWU). Each HWU was a unique A5-sized double-sided colour printed card, containing detailed information about the respective household's water use based on data collected in the previous intensive measurement period. The HWU design work was contracted to a graphic designer with the goal of producing a professional and visually clear representation of the information to be provided. Fig. 2 shows a de-identified example of a data-populated HWU. 


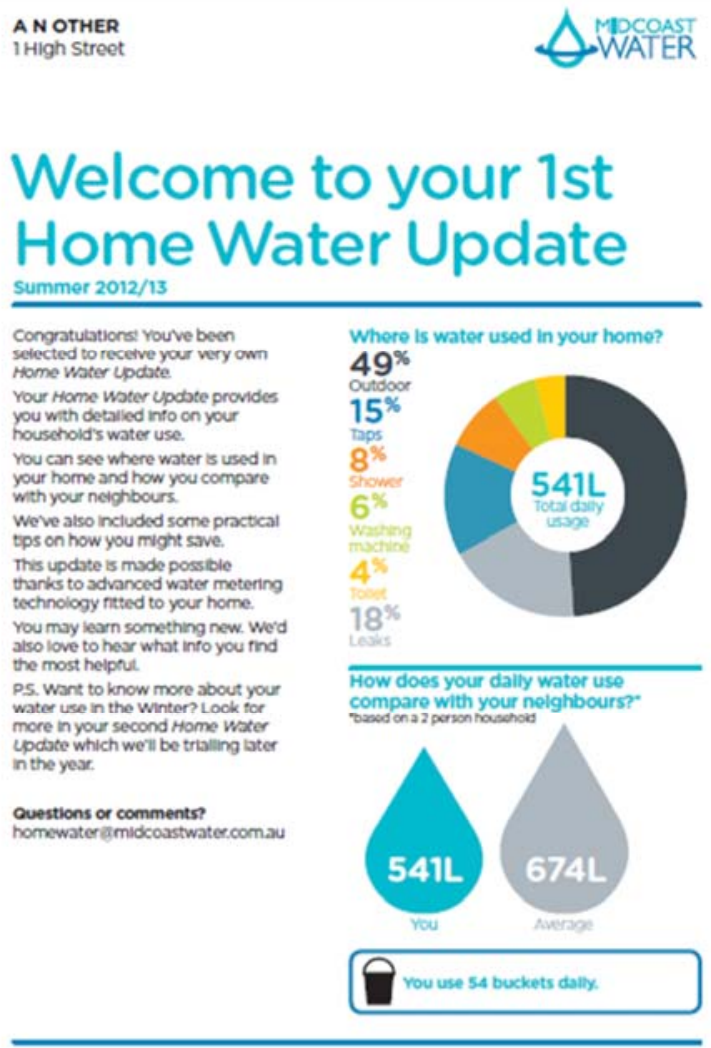

\section{Your home}

This into comes trom smart technologies which estmated water used throughout your home during one month in the summer. Are these results what youdd have expected

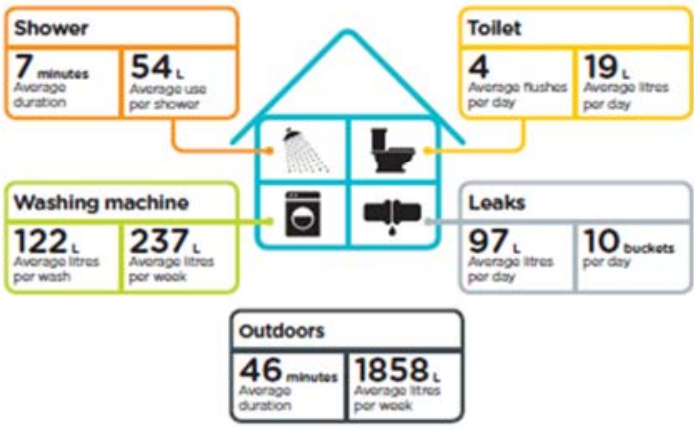

\section{Tips to save water}

\begin{tabular}{|c|c|c|}
\hline \multirow{4}{*}{$\begin{array}{l}\text { it appears that the } \\
\text { blggest part of your } \\
\text { houschoid's usage is } \\
\text { outdoors. } \\
\text { here are some } \\
\text { customised tips to } \\
\text { sive water in your } \\
\text { home and garden. }\end{array}$} & 1 & $\begin{array}{l}\text { Shorten outdoor uses by } 5 \text { mins wach time and you } \\
\text { might save over } 200 \text { ittres a week Thats } 20 \text { buckets }\end{array}$ \\
\hline & 2 & $\begin{array}{l}\text { Check for leask, A lank of } 97 \text { itres per day adds up } \\
\text { to } 35,000 \text { itres a year! seek help from a pumber if } \\
\text { needed. }\end{array}$ \\
\hline & 3 & $\begin{array}{l}\text { Dorrt leave taps ruming Turn them oft when you can } \\
\text { Every minute can save you around } 2 \text { lltrest }\end{array}$ \\
\hline & vis & $\begin{array}{l}\text { lore tips on how to save water, } \\
\text { nwwsavewater.comau }\end{array}$ \\
\hline
\end{tabular}

Fig. 2. Example of the 'Home Water Update' intervention medium - front and reverse sides.

The information provided in the HWUs offered households a quick and detailed overview of their total and relative water use, including summarised measures at end-use levels in greater detail than previously provided. The HWUs' distinctive feature relative to other paper-based feedback mediums (e.g. Britton et al., 2013; Fielding et al., 2013) lay in the inclusion of a variety of customised metrics; and differed from online portals and in-home displays (e.g. Doolan, 2010; Erickson et al., 2012) in providing end-use data. In this way, rather than testing the impact of specific pieces of information, which small samples also do not support, the HWU study enabled households to engage with various different types of customised water and end-use feedback and thus permitted a real-life exploration of interest in different forms of information. This also contrasts with Froehlich et al. (2012), which through the use of prototypes for displays of detailed wateruse feedback, did not provide participants with real actual personalised feedback.

The front side of the HWU:

- informed householders they had been selected for the study, which was framed as a trial; introduced the key features of HWU medium and provided a contact email which was set up for any questions or feedback; - presented an 'end-use pie chart' i.e. the breakdown of the particular household's water consumption between shower, toilet, washing machine, taps, outdoors and leaks; 
- showed a neighbourhood comparison i.e. the average litres consumed daily by the household as compared with the average two-person household within the study. Two-person households represented the majority of study households and were selected as the benchmark for simplified presentation;

- summarised the household's average daily water consumption in terms of

(10L) buckets so the residents could visualise volumes of water.

The reverse side of the HWU contained:

- 'end-use metrics' i.e. detailed measures of water use for specific water using appliances (e.g. average shower duration, average number of toilet flushes per day etc.);

- customised tips on how the household could save water. The customisation typically involved targeting the household's three largest end-uses. Tips were varied between households to explore framing; and care was taken to ensure tips were not repeated for the same household to allow for potential comparisons.

Data collected via the smart meters located on the properties was analysed via SmartMon (Redskink Pty Ltd., 2011) and MS Excel to provide the intervention group households with their first HWU in early May 2013, followed by a second updated HWU in early September 2013. The mailing dates were largely determined by the internal lead times required to collect and process the data and to subsequently produce the HWUs.

A decision was made to mail the HWUs separately from the households' regular quarterly bills. As automated billing is handled externally to MCW, this avoided the need to find a means to coordinate or integrate the mailing of the HWUs with the respective bills for the selected intervention group households independently of other households in the region. It was also perceived that mailing the HWUs separately might improve their visibility and reach, avoiding the HWUs being mistakenly discarded as generic bill inserts.

\subsection{Evaluation survey}

A post-intervention evaluation survey was distributed to all intervention group households in late November 2013, approximately three months after the second and final HWU. The goal of the postal survey was to evaluate the impact of the HWUs by exploring how householders responded to their detailed water-use information. In particular, participants were surveyed on the reach and appeal of the HWUs; changes to household water infrastructure and waterusing behaviours; and awareness of household water use after receiving the HWUs. An incentive of a $\$ 20$ rebate on their water bill was offered to encourage survey participation. Importantly, the evaluation survey allowed the quantitative analysis to be corroborated by insights obtained from reports of participant householders' experiences.

Of the 34 surveys, 23 were returned within the three-week completion deadline and 22 surveys were useable for the majority of questions asked, producing an evaluation survey response rate of $65 \%$.

\subsection{Quantitative measures and analysis}

All quantitative analyses were performed using MS Excel and SPSS (IBM, 2012) version 21. Descriptive statistics were used to identify general tendencies and analyse means and standard deviations. Inferential statistics involving a mixed analysis of variance (ANOVA) were applied to the data to test for significant differences between the sub-groups over time. 
Water consumption data pre- and post-intervention of the intervention group relative to the control group formed the basis of the quantitative analysis. Smart meter data collected in winter 2012 represented the baseline data, while data collected in winter 2013 represented the post-intervention period. This data was used to calculate the average litres of water used per household per day (L/hh/d) and to compare the pre- and post-intervention winters.

Several households were excluded from the analysis. One household lacked a pre-intervention winter baseline; Two moved away from the smart metered properties prior to the post-intervention winter; Two had no postintervention winter data due to meter failure or reader error; and one received incorrect data.

The data sets were characterised by a significant presence of zero or near zero consumption days. To account for householder absence, all zero and near zero consumption days (defined as less than or equal to $10 \mathrm{~L} / \mathrm{hh} / \mathrm{d}$ ) were excluded from the analyses. In addition, a minimum of five valid days per household per measurement period was used to ensure consumption calculations were not distorted by households for which very little data was recorded due to extended absences. These criteria led to a number of additional

exclusions. Therefore in total 11 households (16\%) were excluded from the winter analysis to give 28 intervention group households and 29 control group households.

Despite the study sample drop outs, the intervention and control groups remained similar overall in terms of both the means and variance in preintervention water consumption and in household occupancy rates (Fig. 3). 
a



b

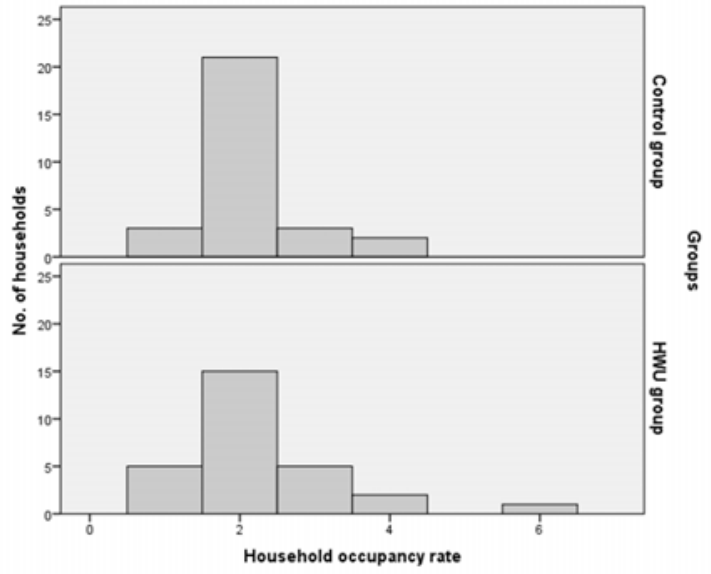

Fig. 3. Histograms of (a) household water consumption profiles and (b) occupancy rates for the final intervention and control groups.

The longer term impact of the HWUs was similarly assessed by comparing baseline data from summer 2012/13 with post-intervention data from summer 2013/14 (four months after the HWU intervention ceased). This analysis was conducted on 26 intervention group and 29 control group households.

\section{Results}

\subsection{Evaluation survey results}

The data obtained from the HWU evaluation survey provided specific insights into the impact of the HWU intervention among participant households. This section reports on the impact of the HWU in terms of (1) the reach and appeal of the HWUs; (2) household water infrastructure changes implemented; (3) behaviour changes enacted; and (4) impact on householders' level of awareness of household water use. 


\subsubsection{HWU program reach and appeal}

The HWU evaluation survey showed that the HWUs achieved a high program reach rate, with all 22 respondents reporting having taken at least a few minutes to engage with the HWUs. Half spent 5-10 minutes on the HWUs, and a couple spent more than this. More than half of the respondents looked at their HWUs more than just once and almost three-quarters compared the two HWUs they received, suggesting the HWUs were used as a reference. More than two-thirds discussed the information in the HWUs on either one or more occasions, which showed the HWUs' reach extended beyond the survey respondents alone.

In terms of appeal, the HWUs were well received by the vast majority of participant households, and all but one household wished to continue to receive HWUs in the future. Some householders particularly expressed notions of value in the ability to monitor their water use and identify opportunities to save via the HWUs.

The HWUs were designed to allow households to experience a range of different types of customised water-use feedback. Responses to the evaluation survey showed that each of the key detailed measures provided (i.e. the end-use pie chart, end-use metrics and neighbourhood comparison) were found interesting by somewhere between 80-90\% of households. Additionally, more than 50-60\% of reports for each of these specific measures stated the particular type of feedback had helped them to save more water at home.

As the end-use metrics was a particularly novel feature in the HWU, households were invited to comment on what they had thought when they saw this information in their HWUs. Here 14 out of the 22 survey respondents provided comments. The end-use metrics were generally described as "interesting" or "very interesting." Some mentioned notions of "surprise" or even "shock" at the amounts of water being used and a wish to do more to save. One household checked their taps and meter to test for leaks as a response. Another concluded they should "Reduce the washing machine usage. Always use half flush in toilets". Finally, a couple of respondents expressed either doubts about the data, or curiosity as to how the end-use data was obtained.

\subsubsection{HWU impact: household water-using infrastructure changes}

Several physical changes to household water infrastructure were reported via the evaluation survey by households after receiving the HWUs. Two of the 21 respondent households (10\%) reported having installed new water-efficient appliances after receiving the HWUs. These involved one new efficient shower head and one new water-efficient toilet. In addition, three households (14\%) reported repairs of leaking household water infrastructure.

\subsubsection{HWU impact: household water-using behaviour changes}

In terms of everyday water-using behaviours, eight of the 21 respondent households (38\%) reported changing their behaviours after receiving the HWUs in order to conserve water used in the home. Specifically, three households were using taps differently e.g. "[we] make sure kids turn off [the] tap always" and "turn off to brush teeth and washing veggies and washing up". Five households reported saving water in the shower by taking "shorter showers" or "turning down" [the flow]. As for toilet flushing, two households reported they were using the "half flush when necessary" and opting to "only 
flush when necessary". Three households used the washing machine more conservatively, by using the machine "less often, [and for] full loads" or "only [for] full loads". Finally, three households reported saving water outdoors, with one explaining they "used the spear point more often" than before.

\subsubsection{HWU impact: changes in awareness of household water use}

A comparison of the baseline survey (conducted at recruitment) and postintervention evaluation survey showed a marked increase in householders' awareness of their water use after receiving the HWUs. Post-intervention awareness scores for the HWU group evaluation survey respondents were much higher than pre-intervention, and furthermore higher than the preintervention scores of both the non-respondents to the HWU evaluation survey and the control group (see Fig. 4).

After receiving the HWUs, all 22 respondents agreed they knew where most water was used in the home. More than 80\% felt they knew their water use, almost double the share pre-intervention. Knowledge of household water-using appliances consumption also increased on a similar scale. More than 90\% felt informed about their water use after receiving the HWUs as compared with just one-third of households pre-intervention. From the surveys an altogether positive impact on awareness was reported, suggesting the HWUs served well as an educational tool among its recipients.

Within the HWU group, pre-intervention awareness was found slightly higher among those who later responded to the evaluation survey than those who did not. However, initial awareness was higher still among the control group. Overall, the HWUs may have reached households with mid-range awareness.

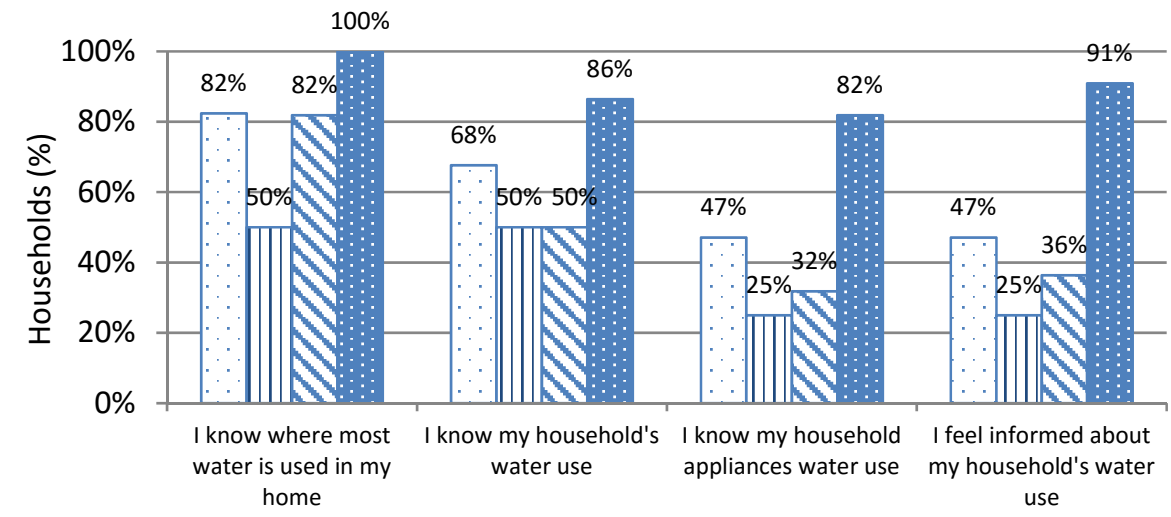

$\square$ Control group $(\mathrm{N}=34)$

$\square \mathrm{HWU}$ group: Evaluation survey non-respondents ( $\mathrm{N}=12)$

$₫$ HWU group: Evaluation survey respondents pre-intervention $(\mathrm{N}=22)$

. HWU group post-intervention $(\mathrm{N}=22)$

Fig. 4. Awareness of household water use pre- and post-intervention. Data presented is based on the share of respondents who either agreed or strongly agreed with each statement. HWU group post-intervention results refer to households that completed the evaluation survey. Pre-intervention results for the HWU group are shown separately for those who did not complete the postintervention evaluation survey.

\subsubsection{Winter analysis of total water use pre-and post-intervention}


Descriptive statistics are shown in Table 1. Initially, the intervention group consumed an average of $373 \mathrm{~L} / \mathrm{hh} / \mathrm{d}$; 8\% less than the control group's average of $405 \mathrm{~L} / \mathrm{hh} / \mathrm{d}$. Post-intervention winter consumption was lower for both groups than at baseline. The intervention group's consumption decreased by $76 \mathrm{~L} / \mathrm{hh} / \mathrm{d}(-20.3 \%)$; and the control group's by $52 \mathrm{~L} / \mathrm{hh} / \mathrm{d}(-12.7 \%)$. Postintervention the intervention group consumed 16\% less than the control group, (compared to the initial 8\% difference). Since the two groups were located in the same geographical area it is reasonable to assume other factors (e.g. weather variables) are likely to have had a similar impact on both. This impact is captured within the control group's change in consumption. The results signal a net impact of $8 \%$ water savings in the intervention group.

Table 1. Descriptive statistics for the control and intervention groups preand post-intervention

\begin{tabular}{|c|c|c|c|c|c|}
\hline & \multicolumn{2}{|c|}{$\begin{array}{l}\text { Pre-intervention } \\
\text { winter }(\mathrm{L} / \mathrm{hh} / \mathrm{d})\end{array}$} & \multicolumn{2}{|c|}{$\begin{array}{l}\text { Post-intervention } \\
\text { winter }(\mathrm{L} / \mathrm{hh} / \mathrm{d})\end{array}$} & $\begin{array}{l}\text { Pre-post difference } \\
(\mathrm{L} / \mathrm{hh} / \mathrm{d})\end{array}$ \\
\hline & Mean & $\mathrm{SD}$ & Mean & $\mathrm{SD}$ & Mean \\
\hline $\begin{array}{l}\text { Control } \\
\text { group }\end{array}$ & 405 & 239 & 354 & 211 & $-52(-12 \cdot 7 \%)$ \\
\hline HWU group & 373 & 220 & 297 & 184 & $-76\left(-20 \cdot 3 \frac{\circ}{0}\right)$ \\
\hline $\begin{array}{l}\text { Group } \\
\text { difference }\end{array}$ & $-32\left(-8 \frac{\circ}{0}\right)$ & & $-57(-16 \%)$ & & $-24(-7.6 \%)$ \\
\hline
\end{tabular}

\subsubsection{Inferential statistics for winter analysis}

A mixed ANOVA performed on the winter data showed a significant main effect of time, $F(1,55)=5.061, p=0.028$, partial $n^{2}=0.084$; an insignificant main effect of group, $F(1,55)=0.827, p=0.367$, partial $\eta^{2}=0.015$; and an insignificant interaction between time and group, $F(1,55)=1.83, p=0.670$, partial $\eta^{2}=0.003$. Overall, this means that the measured effect of the HWU intervention was not significantly different between the intervention and control groups. However, the interaction test may lack statistical power as the modest trial sample size ( $N=57)$ may not have been large enough to detect differences between the subgroups.

\subsubsection{Winter end-use analysis pre- and post-intervention}

Fig. 5 compares pre- and post-intervention winter consumption at end-use levels for the intervention and control groups. Pre-intervention household consumption was approximately equal between the two groups across all enduses except leaks. The control group had an unusually high occurrence of leaks of $42 \mathrm{~L} / \mathrm{hh} / \mathrm{d}$ (10\% of total water use), compared with the intervention group's $15 \mathrm{~L} / \mathrm{hh} / \mathrm{d}$ (just 4\% of total water use). Excluding leak data, intervention and control group households consumed an almost equal amount pre-intervention i.e. 358 and $363 \mathrm{~L} / \mathrm{hh} / \mathrm{d}$, respectively, or a difference of just $1 \%$. Among the remaining end-uses, pre-intervention winter consumption was slightly higher in the intervention group households for shower and toilet uses than the control group.

Post-intervention winter consumption was lower in the intervention group than the control group for every end-use. Relative to the control group, the intervention group obtained marked savings in outdoor (-25\%), washing machine $(-24 \%)$, shower $(-15 \%)$ and toilet $(-10 \%)$ use. Water consumption via leaks was fairly stable for the intervention group across the two periods. 
Interestingly, however, the control group reduced their leakage by $44 \%$ compared to baseline, so a level comparable to the intervention group was recorded.

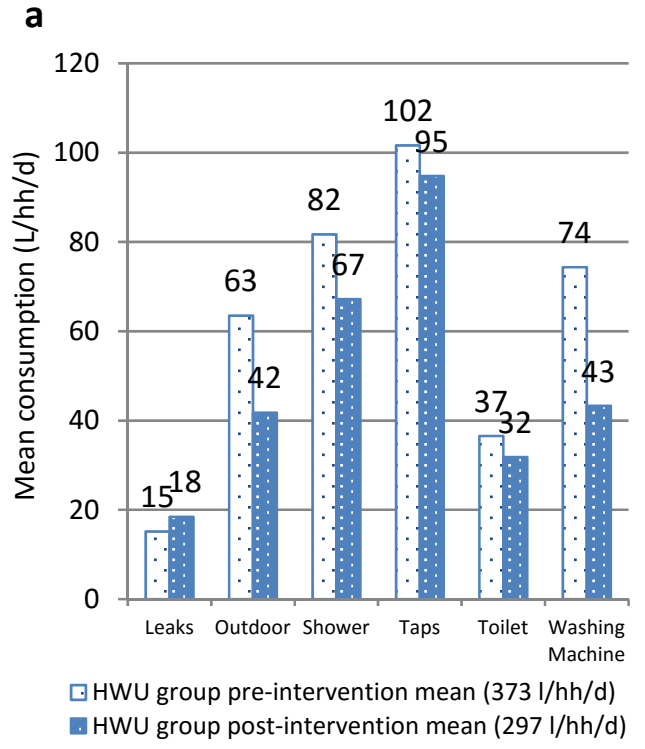

b

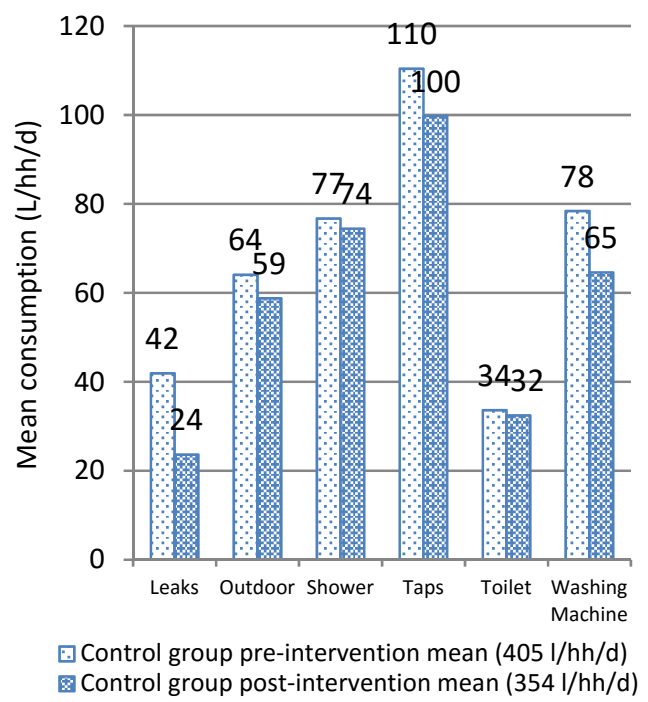

Fig. 5. Pre- and post-intervention winter consumption at end-use levels for (a) HWU group and (b) control group.

End-uses for the control group expressed in terms of consumption shares were very stable between the two winters, each varying by 1-3\%. By contrast, consumption shares for the intervention group showed greater variance preand post-intervention. In particular, the share of water used by the washing machine decreased by 6\% and by outdoor use by 3\%. Conversely, the share represented by taps increased by 5\%. However, all other end-uses retained a share of overall consumption within 1-2\% of the pre-intervention shares. 


\subsection{Longer term (summer) analysis pre- and post-intervention}

In the pre-intervention summer, the intervention group's average consumption was $682 \mathrm{~L} / \mathrm{hh} / \mathrm{d}(\mathrm{SD}=319)$, and was 7\% higher than the control group's 638 $\mathrm{L} / \mathrm{hh} / \mathrm{d}(\mathrm{SD}=293)$. Post-intervention summer consumption increased for both groups, to $763 \mathrm{~L} / \mathrm{hh} / \mathrm{d}(\mathrm{SD}=298)$ in the intervention group (+12\%), and 655 $\mathrm{L} / \mathrm{hh} / \mathrm{d}(\mathrm{SD}=325)$ in the control group (+3\%). The intervention group's consumption was therefore $16 \%$ higher post-intervention than the control group; representing an overall net increase of 9\% relative to the control group.

A mixed ANOVA for the summer data revealed similar results as for winter, but with an insignificant main effect of time, $F(1,53)=1.667, p=0.202$, partial $\eta^{2}=0.031$; in addition to an insignificant main effect of group, $F(1,53)=1.051$, $\mathrm{p}=0.310$, partial $\eta^{2}=0.019$; and an insignificant interaction between time and group, $F(1,33)=0.709, p=0.403$, partial $\eta^{2}=0.013$. Again, the measured effect of the HWU intervention was not significantly different between the intervention and control groups.

Fig. 6 shows pre- and post-intervention summer consumption at end-use levels for the intervention and control groups. The higher level of consumption in the intervention group at baseline applied across most end-uses, with the greatest disparities in tap (+16\%), shower (+15\%) and outdoor use (+6\%); but toilets and leaks consumption was almost equal between the two groups. Only washing machine use was initially lower among the intervention group (-9\%).

End-use data sheds light on the relative increase in the intervention group's water consumption and reveals the intervention group consumed more than the control group for most uses, with the exceptions of showers and toilets. Compared to pre-intervention, the intervention group saved 21\% in the shower and $17 \%$ in the toilet relative to the control group. A notably large difference of $66 \mathrm{~L} / \mathrm{hh} / \mathrm{d}$ in outdoor use in the post-intervention period accounts for most of the final overall difference in consumption between the two groups. Baseline survey data showed the control group had relatively more bores and fewer swimming pools and spas than the intervention group, which may have contributed to this result. 


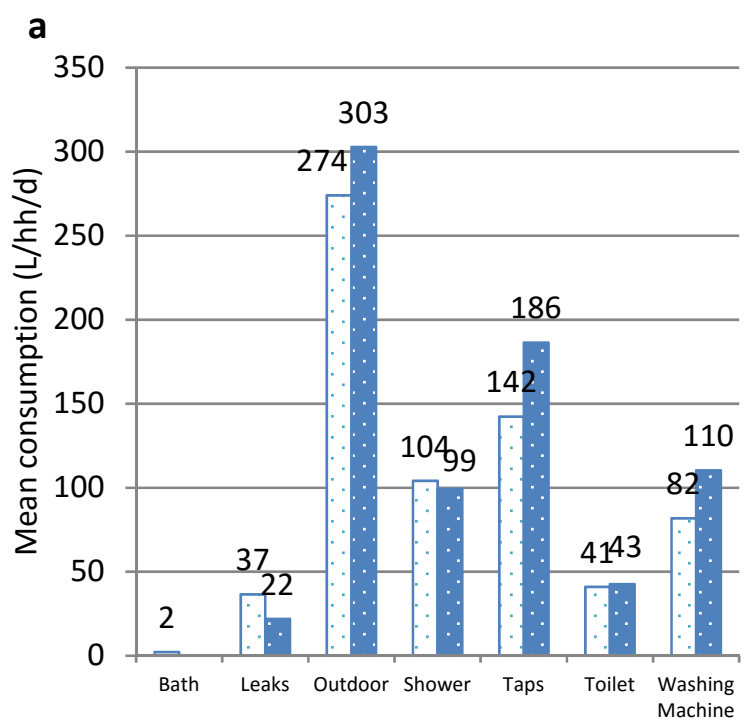

$\square$ HWU group pre-intervention mean $(682 \mathrm{~L} / \mathrm{hh} / \mathrm{d})$

- HWU group post-intervention mean $(763 \mathrm{~L} / \mathrm{hh} / \mathrm{d})$

b



B Control group pre-intervention mean $(638 \mathrm{~L} / \mathrm{hh} / \mathrm{d})$

图 Control group post-intervention mean $(655 \mathrm{~L} / \mathrm{hh} / \mathrm{d})$

Fig. 6. Pre- and post-intervention summer consumption at end-use levels for (a) HWU group and (b) control group.

\subsection{Limitations of the study}

The HWU study was conducted within a pre-existing organisational setting of smart metering, data collection and end-use analysis, which allowed for a relatively low-cost research environment to explore the provision of detailed 
household water-use feedback. However, several research design constraints were experienced as a result of these existing processes.

Due to the data collection process involving intensive measurement only in summers and winters, the HWU study could only capture snapshots of water use pre- and post-intervention. Particularly the baseline data was recorded for only a limited number of days. While due to resource constraints this is not uncommon among intervention studies conducted using smart water metering (e.g. Willis et al., 2010), it is noted that Fielding et al. (2013) were able to collect three months of baseline data. Nevertheless, the HWU study's use of a control group with similar characteristics (i.e. similar previous consumption levels from billing data, the same geographic location and a similar number of occupants) to the intervention group, should have compensated for other external influences, likely to impact equally on both groups (e.g. Climate changes, MCW's other communications e.g. regular billing and rebate program).

The HWU study sample was limited from the outset due to its recruitment from a limited population of households already fitted with smart water meters and the research ethics requirement of informed consent. In retrospect, the statistical power of the analysis could have been improved via additional recruitment efforts to increase the sample size for the quantitative analyses. Alternatively, since the manual production of HWUs for additional households would have been costly, longer measurement periods might have offered a better approach by reducing the variation in average daily consumption, thereby increasing the statistical power of the trial. Nevertheless, and despite sample size attrition, the HWU study sample was not very small, so the idea of providing detailed water-use information could be tested among a fairly heterogeneous group of households. Additionally, for the main purpose of exploring a new method, the overall study sample (N=68) provided ample experience to gain process learning and identify relevant issues.

Unfortunately, due to meter reader error and consequent data loss, hourly consumption data could not be collected throughout the study. This would have allowed for a more direct analysis of the quantitative impact of the HWUs on water consumption over time, in addition to the results from the detailed end-use snapshots. Increased use of more reliable automated meter reading technologies should reduce meter reading errors (Arregui et al., 2006) and support future research into the effectiveness of demand management interventions. In addition, nearer real-time metering and monitoring or analysis will enable faster detection of meter-failures, rather than discovering this only when meters are read through drive-by, as in the present study, and we note is still a method which is commonly used by many utilities.

In addition to detecting completely missing smart meter data for some households, the data analysis met with the challenges of handling zero and near zero consumption days (as in Fielding et al., 2013). While some vacancy of properties is normal, their inclusion would have distorted the analysis. Zero consumption days suggest the householders were simply absent, so for comparability were excluded from the analysis. Near zero consumption days are more challenging and a lower threshold was set for any days in which consumption was equal or below $10 \mathrm{~L} / \mathrm{hh} / \mathrm{d}$. Low consumption may signal the presence of a leak, which needs to be counted as water consumption. However, if occupants are absent, counting the days as a positive consumption day would impact on average consumption for the household since other daily uses 
(e.g. shower, toilet or taps) are zero. Again, the recording of short snapshot periods of detailed data, inherent in the research design, could have altered the impact of zero and near zero consumption days on specific households depending on the particular dates measured, so longer periods are recommended. However, the availability of end-use data can in itself provide useful insights for interpretations of low consumption and the presence of householders.

\section{Discussion}

The sustainable supply of water to the urban residential sector is a constant challenge for the water industry and more effective ways to promote conservation or more efficient use among users are continuously being sought. On the one hand, the HWU study lent support to results from other similar studies (Fielding et al., 2013) that smart water metering and end-use analysis may contribute to the greater goal through better informing householders of their specific uses of water and practical opportunities to save. On the other hand, by exploring the opportunity to provide detailed customised water-use information, the HWU study raised a number of methodological issues relating to current practice, with important implications for the future of household smart water metering and feedback. These issues are elaborated in this discussion section.

Current practice with smart water metering actually varies tremendously between (and even within) water utilities in terms of the technology, scale and data analysis, and depends heavily on project goals and available budgets. However, important trade-offs exist between the resolution of data collected (e.g. typically between 1 minute and hourly data); its suitability for the application of end-use analysis (this is rarely practised since it requires 1 minute data or finer); the measurement periods adopted (i.e. intensive snapshots versus continuous measurement); and the sample size of study households. Without sufficient consideration of the trade-offs new sample-specific insights can still be attained, but as experienced in the current study, high variation in water consumption between households and over time may result in studies which are underpowered to confirm the impacts of interventions.

With regards to the analysis of the interventions, it is worth noting that the use of descriptive statistics is often relied upon when reporting results of smart water metering feedback interventions (e.g. Erickson et al., 2012; Petersen et al., 2007). However, taking the additional step to perform analyses using inferential statistics, as in the HWU study, produced valuable insights into the underlying variation in household water consumption and the statistical power required to detect impacts that might apply at population levels. This is an important consideration, often overlooked in trial-scale water utility projects, but one that warrants further attention.

The HWU study demonstrated that the type of smart metering selected is important in determining the availability of data and the speed of information transmission to customers. The meters used in the present research recorded more detailed water use (at one minute intervals) for just a few weeks each summer and winter due to the logger's limited memory to store the large quantity of data thus collected. In addition, the study experienced a significant lead time between the water consumption events themselves and the related information communication. The use of more advanced metering technologies capable of storing and transmitting in near real-time enables more complete and timelier information for consumers, which 
may promote more immediate responses to unusually high consumption, such as leaks (Doolan, 2010; Erickson et al., 2012). However, for other uses, near real-time feedback may not be required and a one-off or periodic communication, such as the HWUs, could suffice to inform householders on their potential for water savings. More work is required to understand the role of the frequency and continuity of water-use feedback in promoting conservation. Also, since impacts on household water use can diminish over time, particularly after an intervention ceases (as in Fielding et al., 2013), the longer term impact of a sustained HWU-type program requires further exploration.

End-use analysis can open the door to a greater understanding of water use within the home, but current end-use software is not without its challenges and new processes need to be developed for integration with existing information systems. End-use analysis itself requires some manual tagging of water-using events, which is time-consuming and requires industry expertise. Some events can be difficult to interpret, particularly if occurring simultaneously (although this was less of an issue for the low occupancy homes in this study). As costs come down, higher resolution smart water metering may improve the accuracy of end-use analyses and further developments in automating end-use disaggregation (e.g. Nguyen et al., 2013) will improve the prospects for end-use feedback. Since the HWU study further met with the not unusual challenge of changes in occupancy as some properties changed ownership during the study, the automation of smart water metering data processes and services would have to ensure data is linked to the correct owner, something which was more challenging in a manual process of analysis.

The HWUs presented householders with a quick overview of a range of detailed measures of water and end-uses (i.e. an end-use breakdown, neighbourhood comparison, end-use metrics and customised tips). The approach differed from other paper-based mediums (e.g. Britton et al., 2013; Fielding et al., 2013) by including a variety of customised metrics; and from online mediums (e.g. Doolan, 2010; Erickson et al., 2012; Joo et al., 2014; Wetherall, 2008) in providing data categorised by end-use. While the provision of different measures to subgroups of participants allows comparisons of impacts (as in Fielding et al., 2013), further work is required to understand how householders interact with specific and different forms of information. Which information is most useful to householders and what specifically motivates water savings will be explored in forthcoming work.

The impact of more detailed water-use information such as in the HWUs may also vary according to householder profiles. Recent work involving end-use data has shown end-use consumption (Makki et al., 2013), awareness of water use (Beal et al., 2013) and savings via water-efficient devices (Willis et al., 2013) differ according to socio-demographic variables. Therefore still more work is required linking the responses of householders at end-use levels to more detailed water-use information according to householder sociodemographic characteristics. It is fully conceivable that the HWU approach might be better suited to specific demographic groups and more work is required to better understand target audiences. Paper-based customised reports may offer a viable alternative or complement to feedback approaches which make use of in-home or web-based displays accessed via computers and smartphones. Paper reports may offer greater accessibility and familiarity for specific customer segments, including those which still have difficulties accessing digital alternatives (e.g. no computer, smartphone or internet access), or cities which cannot afford to provide in-home displays. 
The HWU study adopted a low engagement strategy whereas other studies (e.g. Anda et al., 2013) used more active approaches in an attempt to encourage householders to conserve water via additional communications (e.g. a more visible program launch or local community engagement event, or phone calls to participants during the trials). Therefore the impact of HWUs on water consumption might be increased if a higher engagement strategy were implemented. The present study showed the potential impact of a low-cost strategy for a water utility involving limited additional interactions with the participants.

The analysis of the smart water meter data in the HWU study revealed some interpretation and analysis by householders will be required since not all relevant information will be available to the utility (see Kempton and Layne, 1994 for a parallel in the energy literature). For example, zero and low consumption days may be difficult for a water utility or data analyst to interpret. However, the respective householders would be better placed to interpret unusual usage (e.g. due to them being away). Similarly, any changes in occupancy (e.g. due to changes in family circumstances) would be unknown to the utility. These fluctuations in activities will influence water consumption and might need to be considered when viewing and comparing wateruse data. This issue was exemplified in one evaluation survey comment that "it would be useful to know the dates that the evaluation of use was carried out - this would allow the household to adjust its use for holidays etc." Alternatively, the more continuous and complete data that is made accessible, the greater may be the capacity for householders to detect important influences on their water use. The presence of unusual events, which can distort averages within a short measurement period (e.g. just two weeks), could be less significant if data is collected during a longer period, or indeed continually. However, the inclusion of dated feedback for shorter periods could be a low-cost improvement to the HWU program.

Finally, analytical challenges identified via the HWU trial are of acute relevance to handling the data that is currently being generated by other applications of smart water metering and water sensors. Accompanying this rapid growth of data availability are the challenges of data cleaning and exploratory data analysis, which precede the application of advanced analytics. Therefore issues we detected with the more manageably sized HWU study's data sets will also need to be considered when analysing the data sets which are now emerging through larger scale implementations of smart water metering.

\section{Conclusions}

The HWU study investigated the potential role for detailed water-use feedback via smart water metering and end-use analysis. The study's mixed method approach involved an original combination of smart meter data and end-use analysis in conjunction with a householder evaluation survey to analyse the role for the paper-based intervention medium.

The evaluation survey showed detailed household-specific water-use information (i.e. end-use breakdown, neighbourhood comparison, end-use metrics and customised tips) was well received by participating householders. Householders expressed value in monitoring their water use via the HWUs and in being able to identify opportunities to save. Awareness of water use increased considerably among HWU recipient households and many reported concrete behaviour changes. These observations suggest a potential role for 
customised, detailed water-use feedback, at least for some if not all customer groups. Clearly, further work is required to optimise approaches and understand target audiences to enable a more significant contribution towards residential water conservation.

Quantitative analysis, which was limited to snapshots of data collected preand post-intervention, initially signalled 8\% savings in water consumption relative to the control group, but this could not be confirmed as statistically significant. Therefore, how significant effects on consumption can be achieved clearly requires additional research involving larger sample sizes and/or more extended measurement. Future work is also required to more fully understand the types of information required by householders to better manage water use, and how householders interact with and interpret these. This would inform the water industry of how best to meet these information demands through smart water metering technologies and associated information services to maximise the potential for water conservation.

Smart water meters are now rapidly being rolled-out in Australia and internationally; increasingly with data resolutions suitable for end-use analysis. However, to date, relatively little data has been disaggregated, so the opportunity for its communication to household customers remains largely unexploited. International conferences are currently demonstrating progressive improvements in smart grid technologies and smart meter data collection, storage, transmission, analysis and communication. Their exploitation may help enable end-use feedback in future, such as provided in the HWU approach and/or via online mediums, and thereby involve customers more fully in the new opportunities being afforded in the digital age.

Finally, the marked variation in household water use found among the study households reinforces that household water use is a complex phenomenon with multiple forces in play. As more data becomes available through more extensive smart water metering and end-use analysis, further research may support a greater understanding of these complex factors to further inform water demand intervention policies.

\section{Acknowledgements}

This research was supported under the Australian Research Council's Linkage Projects funding scheme (LP110200767). The HWU study forms part of a collaborative research program between the Institute for Sustainable Futures at the University of Technology Sydney, MidCoast Water in Taree in NSW, and Griffith University, QLD, Australia from 2012-2015. We thank Graeme Watkins and Chenxi Zeng of MidCoast Water for technical support and SmartMon data analysis, respectively; Tom Boyle and Candice Delaney for overall project support; the householders who kindly participated in the study; Ian Chong for HWU design work; and UTS Printing Services.

\section{References}

Agudelo-Vera, C.M., Leduc, W.R.W.A., Mels, A.R., Rijnaarts, H.H.M., 2012. Harvesting urban resources towards more resilient cities. Resour. Conserv. Recycl. 64, 3-12. doi:10.1016/j.resconrec.2012.01.014

Agudelo-Vera, C.M., Mels, A.R., Keesman, K.J., Rijnaarts, H.H.M., 2011. Resource management as a key factor for sustainable urban planning. J. Environ. Manage. 92, 2295-2303. doi:10.1016/j.jenvman.2011.05.016 
Aitken, C.K., McMahon, A., Wearing, A.J., Finlayson, B.L., 1994. Residential water use: predicting and reducing consumption. J. Appl. Soc. Psychol. $24,136-158$.

Anda, M., Brennan, J., Paskett, E., 2013. Combining smart metering infrastructure and a behavioural change program for residential water efficiency: results of a trial in the southern suburbs of Perth, Western Australia. Water J. Aust. Water Assoc. 40, 66-72.

Arregui, F., Cabrera Jr, E., Cobacho, R., 2006. Integrated Water Meter Management. IWA Publishing, London.

Beal, C.D., Stewart, R.A., Fielding, K., 2013. A novel mixed method smart metering approach to reconciling differences between perceived and actual residential end use water consumption. J. Clean. Prod. 60, 116-128. doi:10.1016/j.jclepro.2011.09.007

Boyle, T., Giurco, D., Mukheibir, P., Liu, A., Moy, C., White, S., Stewart, R., 2013. Intelligent metering for urban water: a review. Water 5, 10521081. doi:10.3390/w5031052

Britton, T., Cole, G., Stewart, R., Wisker, D., 2008. Remote diagnosis of leakage in residential households. Water J. Aust. Water Assoc. 35, 89-93.

Britton, T.C., Stewart, R.A., O'Halloran, K.R., 2013. Smart metering: enabler for rapid and effective post meter leakage identification and water loss management. J. Clean. Prod. 54, 166-176. doi:10.1016/j.jclepro.2013.05.018

Burgess, J., Harrison, C., Filius, P., 1998. Environmental communication and the cultural politics of environmental citizenship. Environ. Plan. A 30, 1445-1460. doi:10.1068/a301445

Darby, S., 2010. Smart metering: what potential for householder engagement? Build. Res. Inf. 38, 442-457. doi:10.1080/09613218.2010.492660

Doolan, C., 2010. Smart metering residential project 2008-2010. Sydney Water. Parramatta, NSW.

Erickson, T., Podlaseck, M.E., Sahu, S., Dai, J.D., Chao, T., Naphade, M., 2012. The Dubuque Water Portal: Evaluation of the uptake, use and impact of residential water consumption feedback, in: CHI 2012, May 5-10, 2012, Austin Texas, USA. ACM, pp. 675-684.

Faruqui, A., Sergici, S., Sharif, A., 2010. The impact of informational feedback on energy consumption - a survey of the experimental evidence. Energy 35, 1598-1608. doi:10.1016/j.energy.2009.07.042

Fielding, K.S., Spinks, A., Russell, S., McCrea, R., Stewart, R., Gardner, J., 2013. An experimental test of voluntary strategies to promote urban water demand management. J. Environ. Manage. 114, 343-351. doi:10.1016/j.jenvman.2012.10.027 
Froehlich, J., Findlater, L., Ostergren, M., Ramanathan, S., Peterson, J., Wragg, I., Larson, E., Fu, F., Bai, M., Patel, S.N., Landay, J.A., 2012. The design and evaluation of prototype eco-feedback displays for fixturelevel water usage data, in: CHI 2012, May 5-10, 2012, Austin Texas, USA.

Fróes Lima, C.A., Portillo Navas, J.R., 2012. Smart metering and systems to support a conscious use of water and electricity. Energy 45, 528-540. doi:10.1016/j.energy.2012.02.033

Giurco, D., White, S., Stewart, R., 2010. Smart metering and water end-use data: conservation benefits and privacy risks. Water 2, 461-467. doi: $10.3390 / w 2030461$

IBM, 2012. IBM SPSS Statistics for Windows.

Joo, J.C., Oh, H.J., Ahn, H., Ahn, C.H., Lee, S., Ko, K., 2014. Field application of waterworks automated meter reading systems and analysis of household water consumption. Desalin. Water Treat. 1-9. doi:10.1080/19443994.2014.889609

Kempton, W., Layne, L.L., 1994. The consumer's energy analysis environment. Energy Policy 22, 857-866.

Liu, A., Giurco, D., Mukheibir, P., Watkins, G., 2013. Smart metering and billing: information to guide household water consumption. Water J. Aust. Water Assoc. 40, 73-77.

Makki, A.A., Stewart, R.A., Panuwatwanich, K., Beal, C., 2013. Revealing the determinants of shower water end use consumption: enabling better targeted urban water conservation strategies. J. Clean. Prod. 60, 129146. doi:10.1016/j.jclepro.2011.08.007

Mayer, P.W., Deoreo, W.B., Iadarola, C., 2000. Water use in new single-family housing in the City of Westminster, Colorado. City of Westminster, CO.

McCormick, K., Anderberg, S., Coenen, L., Neij, L., 2013. Advancing sustainable urban transformation. J. Clean. Prod. 50, 1-11. doi:10.1016/j.jclepro.2013.01.003

McKenzie-Mohr, D., Smith, W., 1999. Fostering sustainable behaviour: an introduction to community-based social marketing. New Society Publishers, Gabriola Island, Canada.

Nguyen, K., Zhang, H., Stewart, R.A., 2013. Development of an intelligent model to categorise residential water end use events. J. HydroEnvironment Res. 7, 182-201. doi:10.1016/j.jher.2013.02.004

Petersen, J.E., Shunturov, V., Janda, K., Platt, G., Weinberger, K., Corfas, R., Dennis, L., Derry, R., Epstein, C., Grossman, J., 2007. Dormitory residents reduce electricity consumption when exposed to real-time visual feedback and incentives. Int. J. Sustain. High. Educ. 8, 16-33. doi:10.1108/14676370710717562 
Redskink Pty Ltd., 2011. SmartMon smartmeter data management software version 1.3 .

Shove, E., 2010. Beyond the ABC: climate change policy and theories of social change. Environ. Plan. A 42, 1273-1285. doi:10.1068/a42282

Stewart, R.A., Willis, R., Giurco, D., Panuwatwanich, K., Capati, G., 2010. Web-based knowledge management system: linking smart metering to the future of urban water planning. Aust. Plan. 47, 66-74. doi:10.1080/07293681003767769

Wetherall, B., 2008. Final report of the Eco-Pioneer pilot program. South East Water. Heatherton.

Willis, R., Stewart, R.A., Panuwatwanich, K., Capati, B., Giurco, D., 2009. Gold Coast Domestic Water End Use Study. Water J. Aust. Water Assoc. 36, $79-85$.

Willis, R.M., Stewart, R.A., Giurco, D.P., Talebpour, M.R., Mousavinejad, A., 2013. End use water consumption in households: impact of sociodemographic factors and efficient devices. J. Clean. Prod. 60, 107-115. doi:10.1016/j.jclepro.2011.08.006

Willis, R.M., Stewart, R.A., Panuwatwanich, K., Jones, S., Kyriakides, A. 2010. Alarming visual display monitors affecting shower end use water and energy conservation in Australian residential households. Resour.

Conserv. Recycl. 54,1117-1127. doi:10.1016/j.resconrec.2010.03.004 